\title{
Urdimento
}

Revista de Estudos em Artes Cênicas

E-ISSN: 2358.6958

\section{A performativização do espaço. \\ Comentários sobre a historicidade de conhecimentos e técnicas na construção de espaços cênicos contemporâneos}

Martina Leeker

Tradução: Stephan Arnulf Baumgärtel e Talita Corrêa

\section{Para citar este artigo:}

LEEKER, Martina. A performativização do espaço. Comentários sobre a historicidade de conhecimentos e técnicas na construção de espaços cênicos contemporâneos. Trad. Stephan Baumgärtel e Talita Corrêa. Urdimento, Florianópolis, v. 2, n. 38, ago./set. 2020.

DOI: http:/dx.doi.org/10.5965/14145731023820200044 


\title{
A performativização ${ }^{1}$ do espaço. \\ Comentários sobre a historicidade de conhecimentos e técnicas na construção de espaços cênicos contemporâneos²
}

Martina Leeker ${ }^{3}$

Tradução: Stephan Arnulf Baumgärtel ${ }^{4}$ e Talita Corrêa ${ }^{5}$

\begin{abstract}
Resumo
A partir de análises de projetos de Edward Gordon Craig, Lois Fuller, David Tudor e Klaus Obermaier, o presente artigo discute os pressupostos discursivos e tecnológicos nas poéticas de uma performativização do espaço. Problematiza as implicações para a agência humana na construção de espaços cênicos que inserem o ser humano de tal maneira nessa dinâmica que a agência dele fica submetida à lógica discursiva dessa construção espacial por meio de uma tecnologia desenfreada.
\end{abstract}

Palavras-chave: História crítica da tecnologia e dos saberes. Dispositivo. Poéticas cibernéticas. Arte e tecnologia.

\footnotetext{
1 o português conhece os verbos performatizar e performativizar, que podem ser substantivados como performatização e performativização. Uma pesquisa em sítios de busca da internet mostrou que o uso do substantivo performativização é mais difundido e mais abrangente no campo acadêmico do que performatização, motivo pelo qual opta-se aqui por performativização.

2 Originalmente publicado em Eke, Norbert Ott; Haß, Ulrike; Kaldrack, Irina. (orgs.) Bühne. Raumbildende Prozesse im Theater. Paderborn: Wilhelm Fink Verlag, 2014, p. 149 - 170. @ Wilhelm Fink Verlag, ein Imprint der Brill Gruppe (Koninklijke Brill NV, Leiden, Niederlande; Brill USA Inc., Boston MA, USA; Brill Asia Pte Ltd, Singapore; Brill Deutschland GmbH, Paderborn, Deutschland)

${ }^{3}$ Doutora e pesquisadora independente. Professora de Teatro e Mídias na Universidade de Bayreuth até 2010, e professora de Ciências das Mídias e Culturas Digitais na Leuphana Universidade de Lüneburg até 2018. Temáticas de pesquisa são sobretudo as relações entre arte e technologia, performatividade e digitalização e teorias críticas das novas mídias.

${ }^{4}$ Professor Doutor do Programa de Pós-Graduação em Teatro (PPGT) do Centro de Artes, Universidade do Estado de Santa Catarina (UDESC). Stephan Arnulf Baumgärtel. stephao08@yahoo.com.br

${ }^{5}$ Bolsista de Iniciação Científica (Cl) no projeto "Encenação enquanto Instalação" do prof. Dr. Stephan Arnulf Baumgärtel.
} 
The performatization of space.

comments on the historicity of knowledge and technology in the construction of contemporary performance spaces

\begin{abstract}
Through an analysis of projects developed by Edward Gordon Craig, Loie Fuller, David Tudor and Klaus Obermaier, this article discusses the discoursive and technológical pressupositions of an poetics of performatization of space. It problematizes the implications for human agency when performance space is constructed so that the human being is inscribed into its dinamics in such a way that his/her agency is submitted to the discoursive logics of this space by means of an technology designed to know no boundaries anymore.
\end{abstract}

Keywords: Critical history of technology and knowledge. Dispositiv. Ibernetic poetics. Art and technology. 
Existe algo que o homem ainda não conseguiu dominar, cujo presente ele nem se permite sonhar e que ainda assim espera que ele se aproxime amorosamente; algo invisível e, no entanto, sempre presente; algo de magia irresistível, pronto para recuar num instante; que persiste na espera de que as pessoas certas se aproximem, para junto com elas levantar voo, para além da terra atravessando todas as esferas - o movimento.

(Edward Gordon Craig,1969, p. 2)

A performance não acontece no tempo, ela cria o seu próprio tempo; ela não acontece no espaço, ela cria o seu próprio espaço.

(Daniel Charles, 2010)

E uma vez que todo o conteúdo é criado em tempo real pelos performers, isso nos mostra o fascínio e também as limitações de nossa inescapável existência no aqui e agora.

(Klaus Obermaier,2010)

\section{Performativização do espaço como dispositivo}

O espaço cênico contemporâneo surge, como podemos dizer de maneira bem sintetizada, de uma "performativização do espaço" que, tanto caracteriza o teatro desde aproximadamente 1900, quanto forma as teorias basilares para as definições espaciais desde os anos 80, do século XX. Na "virada espacial” (ou spatial turn) assim como na "virada performativa" (ou performative turn), que configuram o discurso contemporâneo das descrições teóricas do espaço, a "performativização do espaço" é pensada como uma dissolução de suas condições materiais nos atos e no comportamento de seus "habitantes". São eles que, antes de tudo, geram o espaço. Também no teatro, desde 1900, propõe-se que o espaço cênico seja elaborado pela execução de atos que solapam em sua fragilidade e transitoriedade a ideia de que existe uma espacialidade e uma realidade anterior àquela representada. Sobretudo, no teatro concede-se ao espaço sua própria performatividade. Por isso, dissolvem-se noções de performance que se referem apenas às ações mais ou menos intencionais de atores humanos. O que substitui 
tais noções agora é um entendimento de Performance e Performatividade como sendo a eficácia de uma execução de operações. No que segue, propõe-se uma reconstrução do discurso e da prática dessa performatividade do espaço a partir da história da técnica e dos saberes que a informam. Partimos de duas observações.

Em primeiro lugar, com a performatividade do espaço, perde importância a atenção dada a dispositivos, isto é, as imediações materiais que configuram as percepções e os sujeitos - de forma paradigmática o panóptico de Foucault. Se o espaço não existe de forma independente, mas somente surge a partir do comportamento e da ação humana, ele também não pode configurar a constituição desses comportamentos, a priori. No entanto, no texto que segue, defenderei a tese de que o tópos do "espaço performativo", surgido na virada performativa, é, sim, um dispositivo. Pois apresenta fundamentos bem materiais, ao menos no contexto dos exemplos aqui discutidos, no sentido da produção de um espaço eletromagnético e de um espaço que processa símbolos, porque, mesmo que esses espaços sejam imaginários, na encenação são gerados como reais e efetivos. Além disso, de acordo com o modo de atuação dos dispositivos nesses espaços, são engendrados sujeitos que formam uma rede simétrica de ação por causa da performativização de objetos técnicos, na conexão entre seres humanos e a técnica.

Em segundo lugar, a performativização do espaço é retratada de maneira extremamente positiva, tanto na prática teatral, como na discussão teórica, pois, entre outras coisas, ela liberta o espaço, assim como o sujeito, de diversos dispositivos que desde a renascença fixam o espaço em construções matemáticas e ilusórias, excluindo o sujeito desse espaço para transformar sua materialidade em imagem. No entanto, essa forma positiva de avaliar as referidas viradas disfarça de maneira um tanto idealizante o fato de que tal supervalorização do espaço é um discurso que oculta a virtualização dos agentes nesses espaços tecnicamente performatizados. Uma virtualização que necessariamente faz com que percam o controle sobre a técnica. A reconstrução da performativização do espaço mostrará de que se trata de discursos sobre e a partir de máquinas; discursos presentes 
tanto no teatro quanto na discussão sobre o espaço em geral desde os anos 80, mas desenvolvidos e testados no âmbito teatral. Ignorar tanto a materialidade de dispositivos quanto a discursividade que configura essa supervalorização da performatividade pode levar ao acobertamento do status técnico-material do espaço performativo e da teoria performativa do espaço.

Com base nas diferentes maneiras de performar o espaço no teatro, nos anos de 1900, 1960 e 2000, respectivamente, eu gostaria de mostrar, a título de exemplo, que todas essas formas foram construídas por uma fascínio pelo desencadeamento técnico de coisas e aparelhos. Um aparelhamento que possibilita projetar agentes humanos nesses mundos autorreferenciados e ao mesmo tempo esconder nesse processo a virtualização desses agentes e o controle sobre eles. Essa percepção se ganha a partir de uma historização dos saberes e das tecnologias da performativização do espaço teatral. Já que os teoremas centrais sobre as teorias contemporâneas acerca do espaço teatral foram preconizados a partir de 1900, proponho sua análise também como base de reflexão acerca dos espaços teatrais da atualidade e também das teorias contemporâneas do espaço.

\section{Lógica formal e eletromagnetismo no palco}

A gênese da performativização contemporânea do espaço teatral, numa perspectiva historicizante de suas técnicas e saberes, pode ser localizada por volta de 1900. Neste momento, o teatro foi descoberto como arte espacial por Edward Gordon Craig e Loïe Fuller, entre outros. Com isso, elementos teatrais como movimento, som, corpo, figurino e espaço passaram a ser vistos como meios estéticos independentes do texto. Essa virada corresponde, por um lado, a uma performativização do espaço, na medida em que ele emerge somente das ações fugazes dos atores e junto com elas se desvanece novamente. Por outro lado, o espaço e todas as coisas que estão dentro dele se transformam em parceiros dos atores, transformando-se portanto em uma performance com qualidades 
estéticas próprias.

\section{Simbolismo de Craig. Teatro de formalizações lógicas}

Essa performativização do espaço vem à tona sucintamente no trabalho teatral de Edward Gordon Craig. No seu centro está inscrito, assim podemos ler, um simbolismo teatral universal desenvolvido por ele por volta de 1900. "Simbolismo é, na verdade, algo muito fácil, algo bem normal, facilmente ordenado e universalmente aplicável. [...] Porque o simbolismo não pertence somente aos fundamentos da arte, mas sobretudo aos fundamentos da vida [...]" (Craig, 1969, p.189) ${ }^{6}$. Símbolos invariantes precisariam ter a qualidade de conceitos e todas as coisas deveriam ser possíveis de serem geradas a partir deles, "que o pintor, com certos sinais e formas possa criar a impressão de um burro; e caso ele seja um grande artista, ele expressará a impressão do burro como espécie, a essência espiritual da coisa" (Craig, 1969, p. 55). Para conseguir isso, Craig baniu atores humanos e a cenografia de papel machê do acontecimento cênico. O espaço teatral era, então, constituído por animações de figuras de grandes dimensões, que Craig chamava de super-marionetes, e a "scene", que consistia em elementos cênicos que poderiam ser levantadas e abaixadas do chão e do teto, e em panos e telas móveis. Christopher Innes escreve sobre a "scene":

Ele também acreditava que esse mecanismo poderia ser desenvolvido até o ponto em que um diretor pudesse trabalhá-lo a partir de um console na parte traseira do auditório, durante uma performance, respondendo diretamente aos impulsos emocionais do público. [...] Craig acreditava ter encontrado um tal instrumento na Scene, no qual a voz e a figura humana poderiam ser substituídas por uma luz - sombra movimento através de meios impessoais - e silêncio. (Innes, 1998, p.179).

Portanto, podemos resumir de que mundos artificiais deveriam surgir, sem precisar, necessariamente, do ser humano como seu modelo. Eles seguem muito

${ }^{6}$ Todas as citações são traduzidas por nós a partir desse texto em alemão [NT].

${ }^{7}$ Mantivemos o termo inglês, por sua semelhança com o termo grego da cenografia e para marcar que não se trata nem da ideia de uma cenografia tradicional nem da ideia genérica de uma cena. [NT] 
mais uma lógica própria e deveriam enfeitiçar os espectadores como presença visual e sinais de ordens superiores e sagradas.

A relevância e a repercussão da performativização do espaço no trabalho de Craig, assim como o seu simbolismo podem ser compreendidos no contexto de uma história dos saberes ainda muito pouco pesquisada. A predileção de Craig pelo simbolismo, como elaborou Alexander Firyn (s/a), é construída com base na influência de pensadores e epistemes da lógica formal desenvolvida a partir da década de 1850. Nessa perspectiva, trata-se da ideia de criar símbolos universais e abolir a materialidade, como também os performers vivos em função de suas inadequações formais. Pois, o pensamento-chave da lógica formal na linguística, filosofia e matemática é a possibilidade de poder pensar uma ordem artificial de símbolos universais invariáveis, que funciona como um sistema operacional autorreferente. Nesse sistema, a veracidade e a falsidade de afirmações e conclusões são geradas e testadas com base em alguns axiomas não contraditórios (assim se espera). Na matemática, a partir de 1850/1900, as coisas não são mais somente calculadas. Antes, nos trabalhos de George Boole (1850, in Gaard, 1996) e David Hilbert (1900/1920, in Gaard, 1996), a matemática torna-se operativa, ou seja, ela se torna auto-eficaz, embora de maneiras muito diferentes nos dois pesquisadores. Pois a matemática é projetada como uma calculação, para que se possa tirar conclusões livres de contradições, consistindo em axiomas, definições e regras de comprovação, que determinam as operações necessárias. Inexiste uma relação direta com a realidade, conforme expõe Hilbert (in Gaard, p.15): "Nada é dito sobre a natureza das coisas. Temos a liberdade de imaginar o que quisermos, desde que seja compatível com as afirmações as quais os axiomas determinados explicam”. O código universal pode gerar todo tipo de coisas possíveis, assim como em Craig. "X" e "y" pode tornar-se uma frase, uma fórmula matemática ou uma peça de teatro. Nesses mundos artificiais o que importa é que sejam coerentes em si.

Como se deve apresentar uma "linguagem artística" axiomaticamente regulada e purificada, Craig descreve no cenário de uma encenação de Shakespeare. Por meio de elementos como retângulos e cores ele cria um cenário 
capaz de se transformar de uma montanha para o interior de um castelo. Essas transformações são possibilitadas em razão da sequência lógica de que as paredes são feitas de pedra que são retiradas das montanhas e os móveis são feitos de madeiras que, por sua vez, são extraídas da floresta nas montanhas. Assim, o retângulo cinza de dimensões enormes pode ser visto tanto como montanha ou como interior de um castelo. E uma composição marrom-esverdeada pode também ser vista como floresta ou como mobiliário. Ou seja, trata-se de reduções, bem como de conclusões e classificações lógicas. Craig fala da lei da necessidade, e também da premissa de que as coisas devem estar no lugar certo:

As linhas e as proporções indicaram a materialidade da substância pétrea. A cor (uma cor) e suas diferentes tonalidades trouxeram o tom etérico do vazio nebuloso; [...] Eu sei, que em algum lugar a memória assombra os senhores de que um pouco depois na peça surgem o que deve ser chamado de 'interiores'. Mas, por favor, não se preocupem demasiadamente com isso. Tenham em mente que o interior do castelo é feito do material que vem das pedreiras da montanha. Então, os senhores precisam para isso exatamente da mesma cor que vocês têm nas pedras. [...] Vocês tem que oferecer somente variações sobre o mesmo tema: pedra - marrom, neblina - cinza. E dessa forma você conseguirá atingir, milagrosamente, uma verdadeira unidade artística. (Craig, 1969, p.31).

A partir de uma constelação problemática tipicamente teatral, Craig encontra essa prática de representação, comparável à lógica formal. O ponto decisivo é a seguinte questão: como as aparições de fantasmas na peça de Shakespeare podem ser representadas no palco, sem parecerem ridículas? Ou seja, como trazer à cena aquelas coisas que só podem ser imaginadas ou sentidas, mas que devem permanecer invisíveis. Sua irrepresentabilidade na materialidade leva Craig a uma critica sobre os sinais teatrais e à solução de utilizar super-sinais sobrenaturais e invariáveis. Qualquer material real e sobretudo vivo não seria adequado para o seu trabalho, por sua morbidade e susceptibilidade a erros. Os símbolos invariáveis, no entanto, e a lógica de suas ordens são eternos e independentes da existência em forma de uma matéria real. A lógica se torna quase o meio autêntico da metafísica e do espírito, quando Craig descreve: 
Quando o diretor direciona a sua atenção e a do público somente às coisas visíveis, que são sujeitas à temporalidade, ele rouba desse drama quase toda a sua excelência e todo o seu significado. No entanto, se ele partir do elemento sobrenatural, sem distorcê-lo grotescamente, ele eleva as ação do campo material para a dimensão espiritual e permite se não pelo ouvido físico, mas sim pela escuta da alma - que 'o sussurro solene e incessante dos homens e de seus destinos' se torne audivel; se ele mostra 'os passos incertos e dolorosos da criatura, como ela se aproxima ou se afasta da verdade, da beleza ou de seu deus', ele revela no horizonte, nas camadas mais profundas do rei Lear, de Macbeth, de Hamlet, o murmúrio da eternidade [...]. (Craig, 1969, p. 173).

Portanto, não se trata simplesmente do melhor truque possível para poder representar seres espirituais, mas sim, de uma compreensão metafísica. Nela, a morte, incorporada nas coisas e espaços de dimensões enormes, abre a perspectiva para um ponto zero de uma pureza lógica. Craig discorre dessa maneira:

Eu aspiro à evocação da beleza de um mundo imaginário, capturar por um momento o brilho distante daquele espírito que chamamos de morte. [...] sombras e espíritos me parecem muito mais bonitos e mais vivazes do que os homens e mulheres com quais as nossas cidades estão cheias. [...] - tudo isso, é claro, vai muito além da mera factualidade. [...] Desse mundo ideal podemos ganhar uma inspiração tão poderosa, que eu alegremente, sem hesitar, iria ao seu encontro. (Craig, 1969, p.61).

Podemos resumir que o teatro conforme Craig corresponde a um mover-se por mundos artísticos, esvaziados de pessoas, e que se organizam por conta própria. Performance não é mais a ação intencional de pessoas, mas sim a execução puramente lógica de certos movimentos. Ou seja, trata-se de uma performance pura, realizada por coisas e aparelhos em cima do palco, que deve desencadear dessa maneira a premonição das essências espirituais do ser. Com esta promessa, a performativização do espaço torna-se a base de uma história do fascínio dele, na qual a dissolução das ideias tradicionais do ser humano como sujeito autônomo e do teatro como espaço antropológico são condições prévias para a possibilidade de um conhecimento superior. No lugar da materialidade do espaço entram movimento, transformação e (in-)variações simbólicas como um dispositivo que deve levar os espectadores para o reino do pressentimento de 
ordens superiores. Ao transcender o espaço teatral, portanto, em direção ao reino de puros conceitos, a dissolução das coisas materiais no teatro, bem como sua formalização em matemática, física e linguística, promete um conhecimento superior.

\section{Etéreas danças com o pano, de Lö̈e Fuller}

A dança de Loïe Fuller por volta de 1900, também pode ser vista como uma performativização do espaço, no sentido de libertá-lo em direção a um sistema intrinsecamente ativo e animado. Isso se revela quando a dançarina agita panos de enormes dimensões na sala, que capturam a luz de focos coloridos, mergulhando os panos em cores sempre novas. O resultado é um espaço de luz e cores, no qual a figura da dançarina praticamente se desmaterializa, em um jogo conjunto entre o surgimento e o desaparecimento de sua imagem. Ela não é mais uma intérprete, mas uma operadora que se alinha com o fluxo e os movimentos dos feixes de luz. Este espaço deve, como mostra uma reconstrução desta dança interessada na historização de suas técnicas e saberes, evidenciar o potencial pleno do éter de transmitir todo tipo de substância possível, num momento histórico em que a física do eletromagnetismo começa a dissolvê-lo.

O lado etéreo das danças de Fuller se revela concretamente em Radium Dance, que foi realizado em 1904 na Folies Bergère em Paris, com tecidos de seda auto-luminosos. A dançarina entendia essa obra explicitamente como tomada de posição a favor da existência de forças materiais ("matter forces") esféricas e sobrenaturais. A misteriosa e colorida luminosidade e britho sobre o seu pano radioativo representa para ela, decididamente, o quarto estado da matéria, denominado "estado radiante", supostamente descoberto pelo físico britânico e espírita William Crooke (in Hagen, 2002, p.118 - 131), e que para ambos comprova a existência do éter. Essa visão sobre a radioatividade é descrito por Fuller em um verbete de seu diário de trabalho, direcionado explicitamente contra a física emergente dos elétrons incapturáveis e dos átomos em decomposição, que é associada à dissolução do éter e promovida, entre outras coisas, pela descoberta 
do elemento radium pelo casal Curie. Em sua apresentação, por outro lado, a presença omnipresente do éter deve fazer-se visível. Assim podemos lê-lo, quando esse se materializa supostamente na radiação dos panos. Parece que o mundo arde e brilha por si mesmo, porque o éter está lá e a luz, por meio dele, se transforma em diversas cores.

A insistência no éter, agora já em vias de desaparecimento, revela nos trabalhos de Loïe Fuller, assim como já nos textos de Crooke, uma tradição de interpretação espiritualista dos experimentos etéreos. Pois, na física do éter de Crooke, a matéria radiante, ou seja, as ondas eletromagnéticas, correspondia à substância transmissora dos fenômenos sobrenaturais, como espíritos e pensamentos. Seguindo essa figura de pensamento, Loïe Fuller visa e testa a possibilidade de influenciar seu público por meio de um jogo hipnótico-psicodélico de luzes e cores. Há de se concluir que a materialização do éter nas cores deveria poder colocar o público em uma ressonância psicodélica com as vibrações curadoras e harmonizantes das frequências de luzes e cores.

A performativização do espaço no trabalho de Loïe Fuller implica, portanto, que esse seja carregado de noções sobre o éter, bem como sobre fantasias se não ocultas ao menos psicodélicas-esotéricas. Nesse sentido, Fuller transforma o espaço performativo praticamente em um meio mediúnico, ao liberá-lo de quaisquer amarras no processo de convertê-lo em movimento, transmissão e transformação.

\section{Atores-Agentes em ambientes técnicos libertados por meios eletro-cibernéticos}

Na série de performances 9 Evenings, Theatre and Engineering ${ }^{8}$, apresentadas em 1966 no enorme galpão militar chamado New Yorker Armory, foram evocados e entrelaçados os referidos cenários lógico-formais e ocultistas da

\footnotetext{
${ }^{8}$ Sobre os 9 Evenings, ver a documentação disponível no sítio eletrônico da Foundation Langlois, com palavra de busca 9 Evenings. http://www.fondationlanglois.org/html/f/search.php?MotsCles=9+Evenings\&Submit.x=0\&Submit.y=0\&Format=1. Acesso em: 08 nov. 2019.
} 
performativização do espaço. Criou-se um espaço eletro-cibernético psicodélico no qual os atores, com base em sinais elétricos e vibrações eletromagnéticas, deviam ser incorporados em automatismos e sistemas de controle cibernéticos.

\section{Espaço como sistema de controle eletromagnético}

Nas performances de John Cage, David Tudor, Robert Rauschenberg, Yvonne Rainer, Alex Hay, etc., sinais elétricos foram transmitidos pelo espaço por ondas eletromagnéticas, de modo a provocar tanto nos aparelhos como nos atores efeitos midiáticos. De forma que, neste espaço imaginário, a eletricidade tornouse o menor denominador comum de diferentes fenômenos e entidades, como refletores, alto-falantes, vídeo, controle remoto e, por fim, humanos. Isso permitiu com que, em Grass Field, Alex Hay capturasse ondas cerebrais e as convertesse em sinais elétricos, que foram amplificados e transmitidos a aparelhos que ligavam ou desligavam as luzes e sons ou aumentavam ou diminuíam suas intensidades. John Cage também trabalhou em Variations VII com a captação de sinais cerebrais, para que pudessem ajustar os refletores ou amplificar a acústica. Esses sons do cérebro foram complementados por outros oriundos de batedeiras elétricas, aquários de tartarugas e programas que coincidentemente eram tocados no rádio. Assim foi criada e encenada a aparência de uma traduzibilidade total em um espaço preenchido eletromagneticamente. Tal aparência se torna possível por meio de um conceito de espaço presente nos 9 Evenings, que trata o espaço como um meio para a transferência de sinais elétricos baseados em ondas eletromagnéticas. Ou seja, mais uma vez, aqui, o espaço não é mais pensado como uma entidade estável. Em vez disso, ele se liberta de ser forma fixa, transformando-se em espaço de transferência, onde ocorrem performances de condução e transformação elétrico-analógicas; uma ordem espacial, que no entanto, é um dispositivo, como pretendo mostrar no que segue.

Bandoneon! (a combine). de David Tudor 
Performances de coisas técnicas e espaços midiáticos

Este tipo de performativização do espaço, bem como o seu significado, são particularmente evidentes na performance Bandoneon! (a combine) ${ }^{9}$ de David Tudor. Essa percepção pode ser elaborado a partir de uma contextualização histórica da técnica e dos saberes. Essa contextualização parte da observação de que em Bandoneon, tanto os elementos técnicos quanto o próprio quarto são provocadas a vibrar sonoramente; eles performam. Seguindo uma lógica de celebração, Tudor executou sua composição de dispositivos e instrumentos com a ajuda de seu bandoneón preparado especialmente para isso. Pois ele não produzia sons, mas sinais de controle elétrico que intervinham no fluxo de elétrons ou ondas eletromagnéticas, transformando os aparelhos e até o próprio espaço em agentes criadores. Esse mecanismo de controle e ressonância dos aparelhos, encenado como composição, foi criado através do envio de sinais para carros pequenos, karts, com os quais os alto-falantes e as esculturas sonoras, situados sobre os karts, eram transportados através do espaço. Quando os karts passavam pelos alto-falantes fixos da sala, o encontro de ambas estruturas gerava um feedback acústico de forma imprevisível e progressiva. Criou-se uma autoestimulação do sistema em forma de oscilação ressonante. De tempos em tempos, Tudor interrompia os movimentos do Bandoneon, para deixar com que o armazém reverberasse por si só, criando a impressão de que nessas vibrações provocadas surgissem as de esferas espaciais mais altas.

No mundo oscilante de frequências auto-estimulantes de Tudor, o mundo de pensamento de Loïe Fuller volta a viver nas 9 Evenings, pois emergem figuras espíritas de pensamento, pertencentes ao século XIX. Quando Tudor, leitor comprovado de Rudolf Steiner e membro da Sociedade Antroposófica, desde 1957, desliga sua instalação para fazer ouvir o som esférico do armazém, ele está se preocupando com o som do éter no qual estaria integrada a existência da aura do homem, conforme os conceitos de Steiner. No entanto, Tudor vai além da

Para mais informações sobre essa performance, ver o site da Fondation Langlois, www.fondationlanglois.org, com a palavra de busca Bandoneon! (a combine). 
cosmologia de Steiner, quando the adiciona, por meio do som próprio dos dispositivos elétricos, o som de um techno-éter. Desta forma, a performativização dos aparelhos é acoplada à do espaço de uma maneira diferente. A técnica também é parte do éter cuja ordem se concretiza nela.

O mundo oscilante de frequências auto-estimulantes de Tudor pode ser compreendido antes de tudo no contexto de uma história das mídias espiritista e etérea. Em Bandoneon, as ondas eletromagnéticas soam como prova de uma ordem superior, de caráter integrativo, na qual participam igualmente os seres humanos e a tecnologia.

\section{Sujeitos como agentes-atores}

O artista também reflete sobre o sujeito criado neste espaço performativo, no qual o desempenho das ações em si tem um poder iterativo, transformador e criativo. David Tudor descreve como o performer humano pode perdurar nesta imprevisibilidade e indefinição: "Se você se coloca em uma situação de imprevisibilidade e depois descobre que é completamente possível aceitá-la, você se torna um observador" (Hultberg, 1988, s/p). Entretanto, podemos perceber que este observador possui também elementos de um sujeito agindo intencionalmente, quando Tudor observa: "E é nesse momento que me vem a ideia de que sou eu quem fez isso [...]. Sou eu quem deu vida a essa configuração" (Hultberg, 1988, s/p). Portanto, podemos interpretar de que surge um sujeito na função de um observador de segunda ordem, que acompanha a si mesmo em ação, sendo ele elemento integrante do sistema de feedback, feito de sistemas de condução e controle. Isso leva a uma constituição precária em que o sujeito tem agência, mas mesmo assim só pode observar. O sujeito se torna, no espaço performativo de transmissão e controle, um agente de coisas técnicas, atuando em prol de outra agência, ao mesmo tempo em que é ele quem introduz essas coisas em sua própria composição.

A fim de dominar o mundo técnico libertado de suas amarras, do qual o agente humano entretanto não pode retirar-se devido ao acoplamento elétrico, a 
performatividade é reinterpretada como o simples ato de colocar e executar as coisas e dessa forma ela obtém a agência de ação. Assim, a performatividade não é outra coisa senão a operacionalidade de uma rede sem amarras, constituída de agentes diferentes, um desencadeamento da performatividade numa mera ação e operação. Isso leva a uma mudança técnica de significado: a própria existência se torna a performance de um ser-aímidiático-ecológico.

2000. Klaus Obermaier e seus palcos virtuais com elementos humanos

Quero usar Klaus Obermaier como exemplo final de um espaço cênico gerado e projetado por um computador sobre o palco; um espaço no qual se completam as visões de Craig, a saber, a criação de mundos artificiais a partir de símbolos invariantes em uma lógica formal. Obermaier soluciona o que Craig já havia previsto, mas não podia implementar tecnicamente. No entanto, ao contrário de Craig, Obermaier integra os corpos dos atores ao espaço virtual que é criado por operações simbólicas. Ao invés de simplesmente expulsar o corpo humano do palco, Obermaier utiliza os corpos dos atores de maneiras diferentes para suas projeções, fazendo com que surjam variações virtuais inesperadas. O uso do corpo e do espaço como partes e meio da projeção pode consistir, simplesmente, na interação do corpo com essa, como, por exemplo, em Apparition (2004). ${ }^{10}$ Uma versão mais radical do relacionamento emerge quando as imagens geradas pela tecnologia de dados são projetadas diretamente nos corpos dos artistas, o que resulta em um tipo de animação das imagens por meio dos corpos humanos e que assim se fundem inseparavelmente com elas. Imagem e corpo não poderiam existir sem o outro. Enquanto em D.A.V.E (1999), ${ }^{11}$ os corpos dos bailarinos são sempre visíveis como superfícies de projeção, o que os amplia as possibilidades enquanto elementos de cena, em Vivisector $(2000)^{12}$ as fronteiras entre corpo e

\footnotetext{
${ }^{10}$ Ver http://www.exile.at/apparition/. Acesso em: 09 nov.2019.

${ }^{11}$ Ver http://www.exile.at/dave/. Acesso em: 09 nov.2019.

12 Ver http://www.exile.at/vivisector. Acesso em: 09 nov.2019.
} 
projeção embaçam, de maneira que eles não são mais distinguíveis.
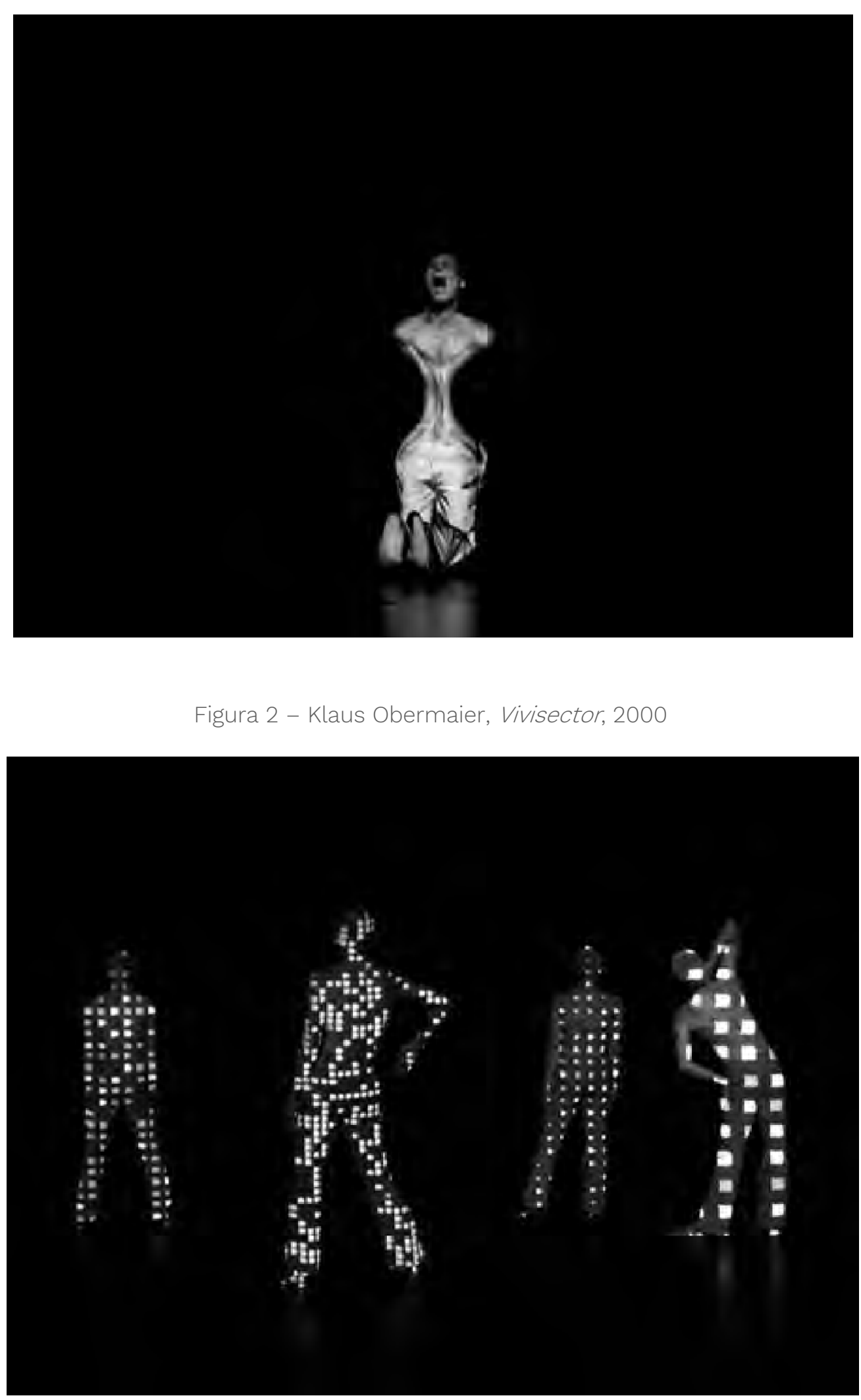


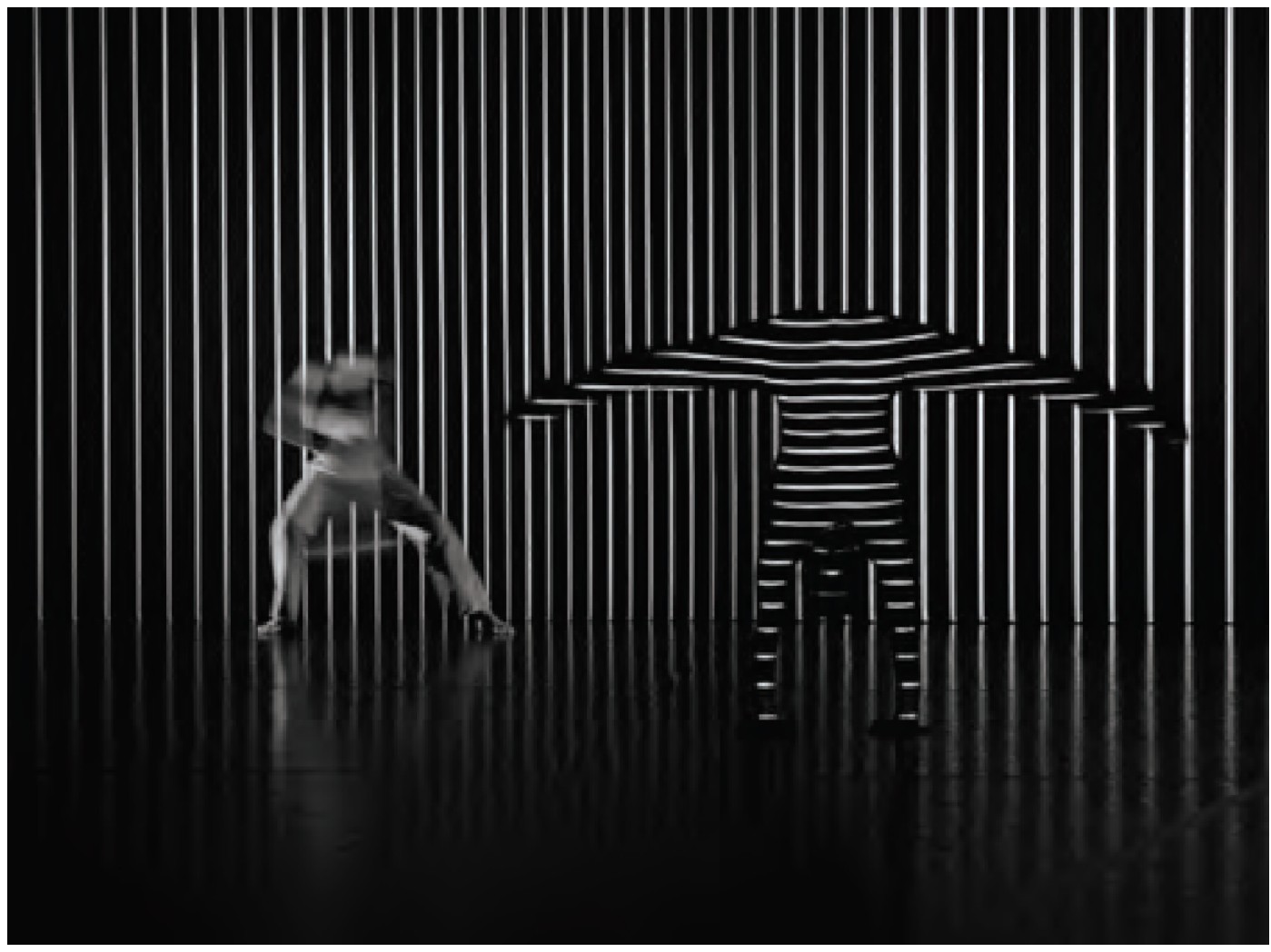

Sacre du Printemps

Enquanto nos supracitados projetos o espaço virtual é traduzido para o físico e nele se funde, na produção de Sacre du Printemps (2006)13 surge um formato diferente tanto da projeção quanto da maneira de relacionar corpo e técnica. Em Sacre, não são feitas projeções sobre o corpo, mas antes, o corpo da dançarina é integrado na projeção enquanto forma virtual. Ao mesmo tempo, o corpo da dançarina permanece exposto em cena, sem transformação técnica, porque atua em um pequeno palco, enquanto a integração da dançarina, em forma de um corpo de dados é visível sobre uma tela de projeção gigante. Portanto, há uma espacialidade dupla, composta por um espaço de dados e um espaço físico. 0 corpo de dados e o mundo pré-moldado podem, então, ser formados à vontade,

${ }^{13}$ Ver http://www.exile.at/sacre/. Acesso em: 09 nov.2019. 
como descreve Irene Judmayer:

Linhas de cor de vermelho encarnado começam uma dança furiosa. Entrelaçam uma mulher cujos membros parecem estranhamente distorcidos. Como braços de aranha, buscam agarrar algo sobre as nossas cabeças. Como numa sala de espelhos, as pernas e os braços se multiplicam. Bolas de corpos disparam pela sala. Pontos de luz explodem. Como uma malha elástica de arame, uma grade digital avança sobre o público. ${ }^{14}$

Figura 4 - Klaus Obermaier, Sacre du Printemps, 2006

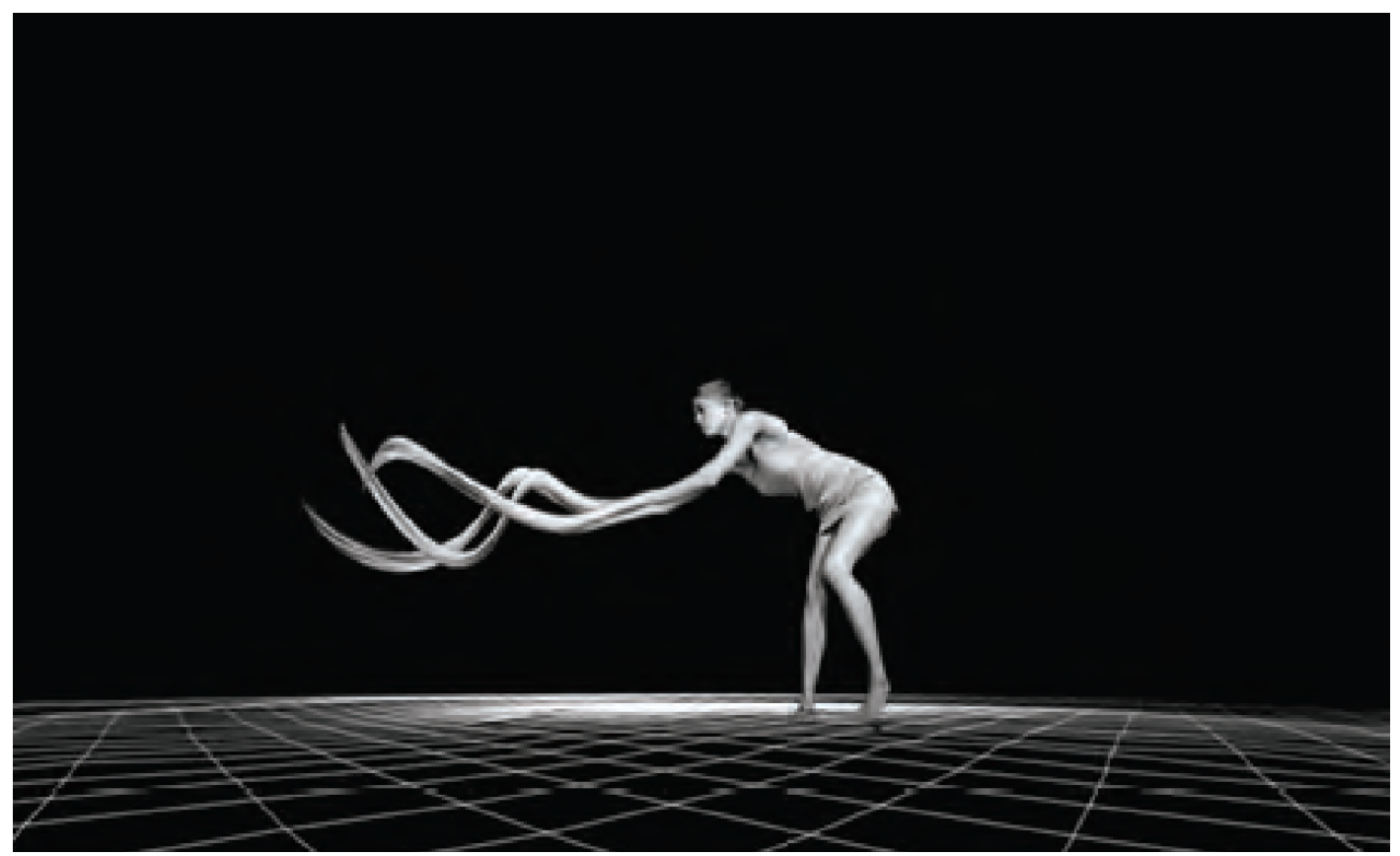

${ }^{14} \operatorname{Ver}$ http://www.exile.at/sacre/reviews de.html. Acesso em: 09 nov.2019. 


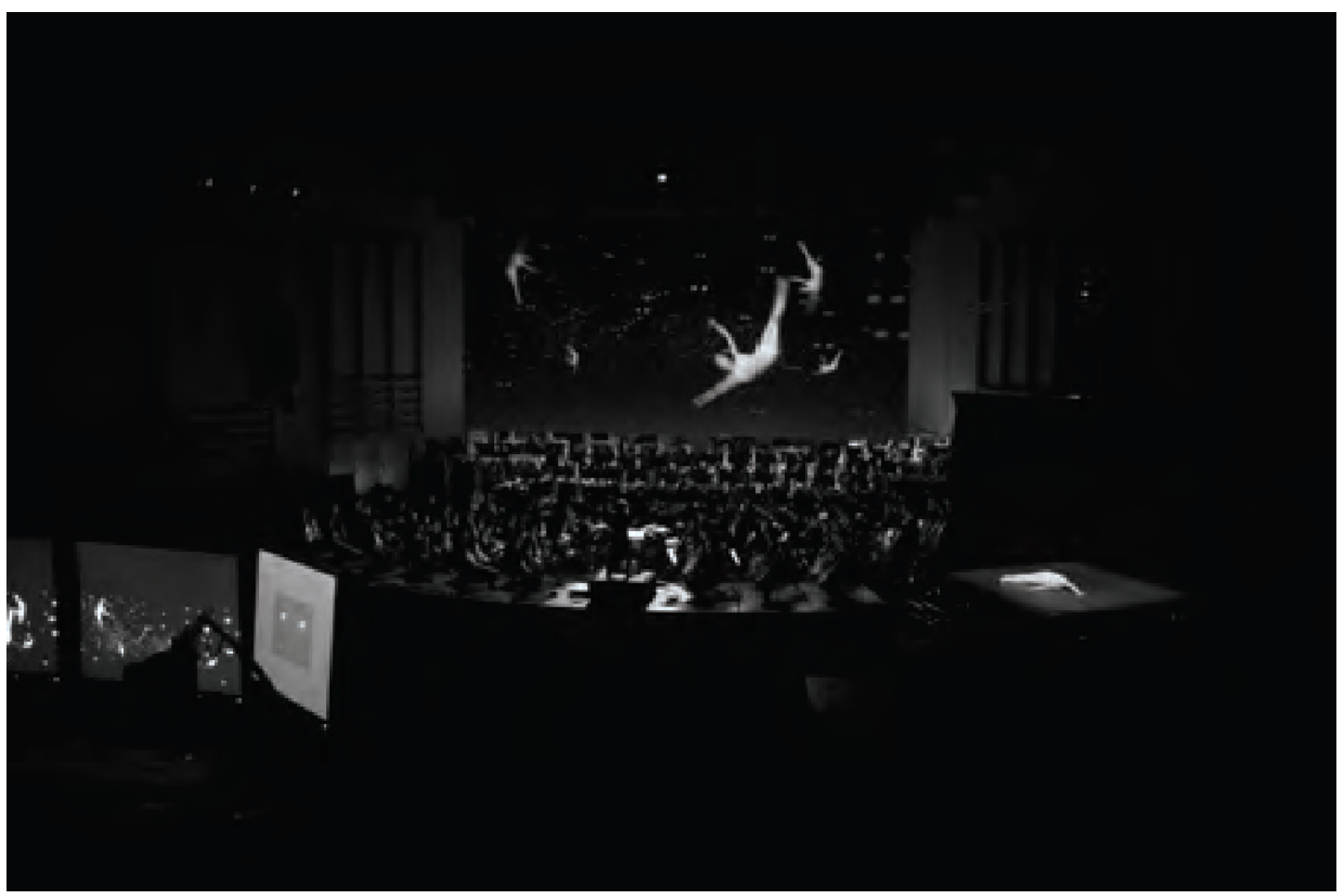

Klaus Obermaier formula seu interesse temática assim:

Hoje, [...] a questão da autenticidade da experiência surge devido à progressiva virtualização dos nossos espaços vitais. É a dissolução de nossa percepção sensorial, o contínuo espaço-tempo, a linha desfocada entre real e virtual, fato e ilusão, que nos leva nos limites da nossa existência. ${ }^{15}$

Na configuração de Sacre, segundo a supracitada reflexão de Obermaier, surgem questões sobre a função da agência humana em espaços e existências virtuais. Nela, a dançarina se torna a fonte exemplar de dados para a projeção gerada pelo computador, ao mesmo tempo em que sua existência física é excluída e tornada irrelevante. Pois o contexto referencial do controle da projeção é transferido do espaço físico para o virtual de maneira que a dançarina tem sua orientação focada na manipulação de sua imagem virtual e não mais em sua dança e existência física sobre o palco. Essa é a diferença decisiva dessa performance

${ }^{15}$ In http://www.exile.at/sacre/project de.html. Acesso em: 09 nov.2019. 
em comparação a outras configurações cênicas interativas. Nela, a dança se evidencia como fundamento de uma transformação calculada em imagens ou som e não é mais encenada como antes, como uma interação de performance e computador. Em Sacre, o corpo dançante e o espaço físico tornam-se um apêndice ao qual os espectadores prestam pouca atenção e que dificilmente podem reconhecer por causa dos óculos 3-D, que os fazem ver o corpo e o espaço digitalizados como projeção de uma ilusão tridimensional. Portanto, cria-se uma performativização do espaço em que o espaço digitalizado produz e controla a performance. Ao contrário do que vislumbra Craig, aqui o ator humano não é expulso da cena, mas é condenado de forma ainda mais radical a tornar-se um apêndice das apresentações. Assim, no modelo cinematográfico teatral de corpo e espaço em Sacre, o modelo humano é engolido pelos mundos gerados pelo computador. Teatro e palco estão dissolvidos em animações, isso significa, em uma espacialidade operacional-performativa. Klaus Obermaier descreve a dimensão espiritual deste teatro de animação:

\begin{abstract}
A imersão dos "escolhidos" na virtualidade, a sua fusão com a música e o espaço, como um "sacrifício" contemporâneo para o novo e incerto, como uma metáfora da salvação e antecipação da felicidade eterna, que as novas tecnologias e as religiões antigas nos prometem. Ou pelo menos como uma nova dimensão da percepção. ${ }^{16}$
\end{abstract}

Por volta de 2000, a existência é, portanto, encenada como um espaço virtual no qual o ator humano se torna um apêndice dos mundos gerados pelo computador, sob a promessa de uma expansão da percepção e da cognição.

Resumo. Contribuições para o debate teórico acerca da virada espacial (spatial turn)

\title{
1. Espaços performativos como dispositivo
}

\footnotetext{
${ }^{16}$ In http://www.exile.at/sacre/project de.html. Acesso em: 09 nov.2019.
} 
A título de finalização, quero avaliar os estudos sobre a constituição do espaço cênico nos exemplos supracitados em relação às suas contribuições para a conceituação teórica do espaço. Com o spatial turn, desde a década de 1980/1990, o espaço enquanto um fenômeno gerado performativamente ganhou foco e a ideia de espaço como materialidade fixa foi, com razão, rejeitada. Mesmo assim, a materialidade do espaço não desapareceu simplesmente, como é sugerido em algumas teorias atuais sobre a espacialidade, nem pode ser negligenciada na apreensão teórica. Antes, negligenciá-la seria ainda mais problemático, porque na materialidade do espaço é que se inscreve o poder. Portanto, faz-se necessário considerar as escolhas da construção espacial como base para uma análise de processos de dominação. ${ }^{17}$

Nos palcos e espaços cênicos que foram aqui citados (como um conjunto de espaços cênicos e teatrais para a produção do olhar e do sujeito) emerge, sem dúvida, uma espacialidade material. Para Edward Gordon Craig, por exemplo, o espaço se torna uma fenômeno ordenado produzido por portadores de símbolos em movimento constante, o que corresponde a sua operacionalidade como dispositivo. Nessa ordem, o observador se sente exposto a uma constante mudança e provocado a fazer uma leitura lógica que o permite localizar-se, ao mesmo tempo em que dissolve essa localização na constatação de uma transformação permanente. O espaço cênico é, portanto, um meio, no sentido de configurar a percepção e a subjetividade.

Klaus Obermaier, em seu Sacre, mostra que o espaço é constituído pela medialidade, que o medium se torna espaço. O espaço d a apresentação foi dividido em diferentes espacialidades e lugares, como o espaço da orquestra, a superfície de projeção do mundo virtualmente calculado, o pequeno palco da dançarina e as fileiras de assentos do público. Ou seja, o espaço se torna um conjuntura relacional que direciona a percepção por meio de sua configuração e das ações que acontecem nele e que regulam a atenção dos espectadores. E ainda, ao mesmo tempo, esse espaço deve ser visto com o auxílio de aparelhos,

17 Prestar atenção ao espaço em sua materialidade, portanto, não implica em não considerar como o espaço surge da interação com uma realidade dada e de sua percepção que muda com as condições técnicasmediais e os contextos históricos daquilo que qualifica como saber. 
porque a ilusão tridimensional das projeções só é alcançada usando óculos adequados. Esta constituição dupla do espaço, que consiste em arranjo espacial e uma configuração perceptiva, é muito importante para a ampliação das discussões teóricas acerca do espaço. Pois, nesses exemplos, o espaço está presente em sua materialidade física e, ao mesmo tempo, existe apenas por meio de sua mediação midiática, ou seja, a percepção dos espectadores que é mediaticamente embasada ou historicamente formada. E, nessa constituição do espaço em Sacre, na percepção mediaticamente instruída, o espaço real e virtual não mais competem nem se substituem. Antes, existem lado a lado como simples possibilidades. Esse posicionamento relacional é criada pelo corpo da bailarina, que só pode ser transformado em cálculos digitais de forma limitada e, portanto, serve como um ponto de referência para as fronteiras e transgressões entre o real e o virtual. A contribuição de Sacre para a discussão acerca do espaço consiste na exposição de que o estado da percepção, formada em sua historicidade e agora embasada nas mídias atuais, se torna condição da possibilidade de espaço.

Finalmente, em 9 Evenings ficou claro que o espaço é acima de tudo imaginário. Pois se conjurou um mundo imaginário para dentro do Armory, esse enorme armazém militar como um local de atuação, em que as posições dos espectadores e atores primeiro tinham que ser criadas e que eram diferentes para cada performance. O espaço enquanto transmissor de sinais tornou-se um signo de ordem superior e foi sobrescrito por metáforas que correspondiam a experiências físicas, por exemplo a ressonância psicodélica bem como a qualidade dos sons em Bandoneon de Tudor. O efeito dessa sobrescrita foi a criação de um espaço imaginário, preenchido eletromagneticamente, onde diferentes agentes devem oscilar e transmutar uns nos outros. Assim, surgiu um espaço imaginário através das performances de seus moradores técnicos e humanos, que, não obstante, concretizou-se materialmente e impactou sobre os corpos e sobre a formação do sujeito. Essa concepção, entretanto, só foi reconhecido através de uma reconstrução da história da técnica e dos saberes humanos.

Como característica sistemática para determinar teoricamente o espaço, tem-se, então, por um lado que o espaço imaginário depende da historicidade do 
conhecimento e da percepção. Por outro lado, torna-se evidente que dispositivos são também imaginários; algo que também deve ser válido quando - ao contrário do que ocorre, por exemplo, em Bandoneon - estamos perante uma construção física que dirige a visibilidade e interpela o olhar.

Vamos resumir as contribuições do teatro para a teoria do espaço. Torna-se evidente, primeiro, que o espaço, mesmo que surja antes de mais nada por meio de ações e realizações culturais, é, entretanto, em sua materialidade um dispositivo, mesmo que a materialidade seja encenada ou criada imaginariamente. Em segundo lugar, vimos que a materialidade pode ser sobreposta, complementada ou transformada pela medialidade. O espaço é sempre uma multiplicidade de possibilidades, inseparável das condições midiáticas dessas.

\section{Perfomativização do espaço como uma "história de seu fascínio"}

Por fim, se torna óbvio, com base nos exemplos supracitados, que uma avaliação positiva do spatial turn, que nada mais é que uma versão do performative turn, enquanto libertação da existência num espaço de afetação e movimento, não deve ser aceita precipitada e acriticamente. Pois a reconstrução historicizante das técnicas e dos saberes envolvidos mostra que essa performativização se situa numa história de fascínio pela a mediação efetuada por mundos tecnicamente desenfreados. Um fascínio que fica cego em relação às impossibilidades dessa mediação e as dissolve ultimamente numa visão de agência compartilhada.

Assim, com base no discurso e na prática da performativização do espaço, o teatro poderia ser reconstruído como uma instância cultural, usada para lidar com uma técnica desenfreada, ao performatizar o espaço e entrelaçar ele com o agente humano em uma rede, ou - como em Obermaier - ao permitir que o agente humano seja apreendido na rede e recriado enquanto provedor de dados. De forma que a performativização do espaço trata do fim de um modelo instrumental, comunicativo e interativo entre homem e tecnologia. Pois, se por um lado, nasce no lugar deste modelo uma existência mediada por um animismo elétrico, como 
delineado nas danças com panos de Loïe Fuller ou em 9 Evenings, por outro lado, é evidenciada a criação de mundos artificiais, que não precisam mais dos humanos como modelos ou como instâncias controladoras, já que seguem sua própria lógica.

Reconstruir a performativização do espaço contemporânea em termos de uma história da tecnologia e como a história de fascínio por uma mediação impossível, significa o mesmo que desvendar seus segredos. O seu ponto de fuga é, pois, desde 1900 a despedida do ator humano dos palcos e a substituição de sua posição por operações simbólicas universais. Deste ponto de vista, o teatro contemporâneo com espacialidades geradas por computadores é apenas uma consequência coerente, mas, do ponto de vista da história dos saberes, não chega a ser um desenvolvimento novo. Esse enfoque do teatro no espaço corresponde, portanto, a uma despedida do agente humano. Em seu lugar surgem mundos artificiais auto-organizados. Nessa história de fascínio pelo desenfreamento de coisas técnicas, está sendo supervalorizado e parcialmente mascarado o fato de que nesses mundos de coisas o ser humano - como sujeito capaz de exercer agência - pode desempenhar, em termos epistemológicos ou técnicos, um papel apenas virtual ou talvez nem precise mais desempenhar papel de agente algum. Pois, a performativização do espaço é um discurso de máquinas, que se baseia na expulsão do ser humano do palco e na ocupação desse por fantasmas e símbolos invariantes, aprovando esse processo por meio de performances. Nesse contexto, dissolver a materialidade de dispositivos no discurso atual sobre a espacialidade ganha uma relevância aguda, já que parece favorecer ainda mais a implementação de mundos artificiais e auto-organizados.

Se essa história de fascínio não for levada em consideração, corremos o risco de desenvolver uma antropologia que não reconhece seu embasamento em discursos marcados pela lógica de máquinas ou suas dependências inconscientes da tecnologia. Esta conclusão não se baseia na ideia de que existe algo como um elemento antropológico inalterável. O "ser humano" faz parte do seu ambiente técnico. Entretanto, dentro desse ambiente, ele não se constitui unicamente por meios tecnológicos, mas também por autodescrições reflexivas-discursivas e 
afirmativas em forma de dispositivos. É importante investigar e compreender os modos de constituição, reconhecer sua gênese e seus efeitos, e observá-las criticamente em materialidade e discurso, exatamente nesse momento de transição para uma existência marcada pela economia midiática e seu desenfreamento por meio de coisas e espaços enfaticamente técnicos.

\section{Referências}

CHARLES, Daniel. "The concept of ... (here and now)." Sobre a coreografia midiática de Klaus Obermeier, 2010. Disponível em http://www.exile.at/concept/project.html. Acesso em: 05 jun. 2020.

CRAIG, Edward Gordon. über die kunst des theaters. Berlin: Gerhardt Verlag, 1969.

DINKLA, Söke \& LEEKER, Martina (eds.). Tanz und Technologie. Auf dem weg zu medialen Inszenierungen. Berlin: Alexander, 2002.

FIRYN, Alexander. Theaterpoesie und Mathematik. Dissertação não publicada, Freie Universität Berlin, Institut für Theaterwissenschaften, sem ano.

GAARD, Bert. Die Rästel der Welt. Gedanken zur Situation der Zeit. 1996. Publicado e disponível em http://www.ingo-tessmann.de/sofie/welt.pdf. Acesso em: 05 jun. 2020 .

HAGEN, Wolfgang. "Loie Fuller. The shock of eletricity and the Technological History of Modern Dance or the Overewhelmingness of technology and the Possibilities of Art”. In: DINKLA, Söke \& LEEKER, Martina (eds.). Tanz und Technologie. Auf dem weg zu medialen Inszenierungen. Berlin: Alexander, 2002.

HULTBERG, Teddy. "I smile when the sound is singing through the space." An Interview with David Tudor by Teddy Hultberg, em Dusseldorf, 17/08/1988. Disponível online em http://davidtudor.org/Articles/hultberg.html. Acesso em: 09 nov. 2019.

INNES, Christopher. Edward Gordon Craig - A Vision of Theater. London e New York: Routledge, 1998.

JUDMAYER, Irene. "Jubelstürme im Brucknerhaus". In: Oberösterreichische Nachrichten, 12.099.2006, disponível em http://www.exile.at/sacre/reviews de.html. Acesso em: 09 nov. 2019.

OBERMAIER, Klaus. "The concept of ... (here and now)". Sobre a coreografia 
midiática de Klaus Obermeier, 2010. Disponível em http://www.exile.at/concept/project.html. Acesso em: 05 jun. 2020.

Recebido em: 3/07/2020

Aprovado em: 3/07/2020 